\title{
Effect of Early Intervention Applied to Patients with Chronic Obstructive Pulmonary Disease at Different Stages
}

\author{
W Lei, M-H Chen, Y-C Pan, C-Y Chen, Y-L Cai
}

\begin{abstract}
Objective: Early intervention in chronic obstructive pulmonary disease (COPD) includes health education, smoking cessation, pulmonary rehabilitation and enhancing immunity (administration of influenza vaccine and polysaccharide nucleic acid fraction of bacillus Calmette-Guerin [BCG-PSN]). The effect of early intervention was investigated systematically in patients with COPD at different stages.

Methods: We enrolled 422 patients with COPD at different stages without symptoms and then randomly assigned them to intervention and control groups. The intervention group was provided with early intervention and usual care while the control group was only provided with usual care. One year of follow-up was performed to observe forced expiratory volume in one second (FEV1), FEV1/forced vital capacity (FVC), and the ratio of patients with acute exacerbation (number of patients with acute exacerbation/total of patients).

Results: The values of decline in FEV1 and FEV1/FVC were significantly lower in the intervention groups of stage I and II than control groups (all $\mathrm{p}<0.05)$, but not significantly lower in the intervention groups of stage III and IV than control groups (all $\mathrm{p}>0.05$ ). The ratios of patients with acute exacerbation were lower in the intervention groups of all the stages than the control groups $(\mathrm{p}<0.05)$. Conclusion: Early intervention could slow the decline of FEV1 and FEV1/FVC in patients with COPD in stages I and II, but not in stages III and IV. Early intervention could also prevent patients with COPD from getting acute exacerbation and improve their quality of life in all the stages of the disease.
\end{abstract}

Keywords: Chronic obstructive pulmonary disease, early intervention, FEV1, FEV1/FVC, forced expiratory volume in one second, forced vital capacity

WIMJ Open 2014; 1 (2): 31

\section{INTRODUCTION}

Chronic obstructive pulmonary disease (COPD) is a frequent kind of chronic respiratory disease with high and increasing prevalence, morbidity and mortality, and it has become a major public health problem worldwide $(1,2)$. Chronic obstructive pulmonary disease is divided into four stages, based on forced expiratory volume in one second (FEV1)/ forced vital capacity (FVC), FEV1 and clinical symptoms. In stage I (mild), FEV1/FVC $<70 \%$ and FEV1 $\geq 80 \%$ of the predicted value, and the patient may present with or without chronic symptoms (cough and expectoration); in stage II (moderate), FEV1/FVC $<70 \%$ and $\leq 50 \%$, FEV $1<80 \%$ of the predicted value, and the patient frequently presents with chronic symptoms (cough, expectoration and dyspnoea after action); in stage III (severe), FEV1/FVC $<70 \%$ and $\leq 30 \%$,

From: Department of Respiration, Affiliated Dongguan Shilong Peoples' Hospital of Southern Medical University, Dongguan City, China.

Correspondence: Dr M-H Chen, Department of Respiration, Affiliated Dongguan Shilong Peoples' Hospital of Southern Medical University, No. 1 Xianglong Road, Shilong Town, Dongguan City, 523326, China. Fax: +86769-81368360, e-mail: wqg801021@163.com
FEV1 $<50 \%$, and the patient generally presents with chronic symptoms (cough, expectoration and dyspnoea) and frequent occurrence of acute exacerbation; in stage IV (very severe), FEV $1 / \mathrm{FVC}<70 \%$ and $\mathrm{FEV} 1<50 \%$ or $30 \%$, and the patient may suffer from chronic respiratory failure and even pulmonary heart disease (cor pulmonale), right heart insufficiency or failure. In China, the ratio of COPD patients is $8 \%$ of the population aged 40 years and older (3) and the trend is increasing (4), thus the prevention and treatment of COPD should be reinforced.

Early intervention is very important in the treatment and rehabilitation of patients with COPD. Specific measures include health education, smoking cessation, pulmonary rehabilitation and enhancing immunity [administration of influenza vaccine and polysaccharide nucleic acid fraction of bacillus Calmette-Guerin (BCG-PSN)] (5-7). Early intervention can be applied to the general population, the highrisk population and COPD patients. Previous studies have shown that early intervention can significantly reduce the annual rate of decline of FEV1 and FEV1/FVC and cumulative mortality, and meanwhile enhance the rate of smoking cessation in the general population (8-10). Early 
intervention can prevent stable COPD patients from having acute attacks, reduce the times of outpatient and inpatient treatment, improve the quality of life, and save medical resources and expenses in COPD patients. But the effects of early intervention have not been researched systematically in COPD patients at different stages. Additionally, it is not known whether early intervention delays the decline of pulmonary function in patients with COPD at different stages and shows a difference among these delays.

In this paper, we chose several common measures of early intervention and applied them to COPD patients at different stages. The pulmonary function and number of patients with acute exacerbation were then followed-up. We aimed to determine whether early intervention delayed the decline of pulmonary function in COPD patients and whether early intervention had any relation to stage of disease.

\section{SUBJECTS AND METHODS}

\section{Study population}

Firstly, we chose five communities randomly in Dongguan city in China. Secondly, we carried out a screening survey and got 1091 persons aged 40 years and above in the five communities, and then identified 206 COPD patients by SGRQ scores (St George's Hospital Respiratory Questionnaire) and pulmonary function tests. Thirdly, we got 216 COPD patients from review of the case history at our hospital. Lastly, all the COPD patients were enrolled in the study and randomly assigned into intervention or control groups. Table 1 shows the baseline characteristics of study participants.

The intervention groups were provided with early intervention including health education, smoking cessation, pulmonary rehabilitation, enhancing immunity (administration of influenza vaccine and BCG-PSN), taking bronchodilators and inhaling corticosteroids besides the usual care. Health education was carried out by health manuals, lectures, free consultation and relevant knowledge competitions aimed at improving the knowledge about COPD, eliminating harmful habits and behaviours. Smoking cessation was advised by lectures on the adverse effects of smoking and the benefits of smoking cessation. Psychosocial support was also provided to help smokers cope with withdrawal symptoms. Pulmonary rehabilitation included physical exercise, pursed lip breathing and abdominal breathing. Influenza vaccine and BCG-PSN were administered quarterly. The control groups were only provided with the usual care. The compliance of the intervention groups was checked regularly. After one year of follow-up, the FEV1 and FEV1/FVC, and number of patients with acute exacerbation were compared between the intervention and control groups. After the study, all the participants were managed according to the Guidelines for the Diagnosis and Management of Patients with COPD (2011). Permission was obtained from the Ethics committee of our hospital and all the participants gave informed consent.

\section{Statistical analysis}

The gender ratio was compared between the intervention and control groups using Chi-squared test. Age and body mass index (BMI) between the intervention and control groups were compared using Student's $t$-test. Forced expiratory volume in one second and FEV1/FVC in the baseline survey were compared to the data one year later using Student's $t$ test for all the groups. The differences in FEV1 and FEV1/FVC between the baseline survey and one year later in the intervention groups were compared to the control groups using Student's $t$-test. The ratios of patients with acute exacerbation in one year between the intervention and control groups were compared using Chi-squared test. The statistical analysis was performed with SPSS version 17.0. Significance was set at $\mathrm{p}<0.05$.

\section{RESULTS}

All the participants completed follow-up. The ratio of gender, age and BMI were not significantly different between the intervention and control groups (Table 1). Forced expiratory volume in one second and FEV1/FVC after one year of follow-up were lower than the baseline data for all the groups (Table 2). The values of decline in FEV1 were significantly lower in the intervention groups of stage I and II than the

Table 1: Baseline characteristics of all the groups

\begin{tabular}{|c|c|c|c|c|}
\hline & & $\begin{array}{c}\text { Number of } \\
\text { participants } \\
\text { (male/female) }\end{array}$ & Age (years) & $\begin{array}{l}\text { Body mass index } \\
\text { (BMI) }\end{array}$ \\
\hline \multirow[t]{3}{*}{ Stage I } & Intervention group & $44 / 13$ & 61.3 & 22.96 \\
\hline & Control group & $43 / 14$ & 60.9 & 23.24 \\
\hline & $p$ & $>0.05$ & $>0.05$ & $>0.05$ \\
\hline \multirow[t]{3}{*}{ Stage II } & Intervention group & $29 / 13$ & 63.5 & 22.35 \\
\hline & Control group & $27 / 15$ & 63.3 & 24.12 \\
\hline & $p$ & $>0.05$ & $>0.05$ & $>0.05$ \\
\hline \multirow[t]{3}{*}{ Stage III } & Intervention group & $57 / 20$ & 65.5 & 21.37 \\
\hline & Control group & $60 / 17$ & 65.8 & 22.43 \\
\hline & $p$ & $>0.05$ & $>0.05$ & $>0.05$ \\
\hline \multirow[t]{3}{*}{ Stage IV } & Intervention group & $32 / 10$ & 68.1 & 20.38 \\
\hline & Control group & $33 / 8$ & 67.9 & 21.08 \\
\hline & $p$ & $>0.05$ & $>0.05$ & $>0.05$ \\
\hline
\end{tabular}


Table 2: Forced expiratory volume in one second (FEV1) and FEV1/forced vital capacity (FVC) of baseline survey and one year later in intervention and control group

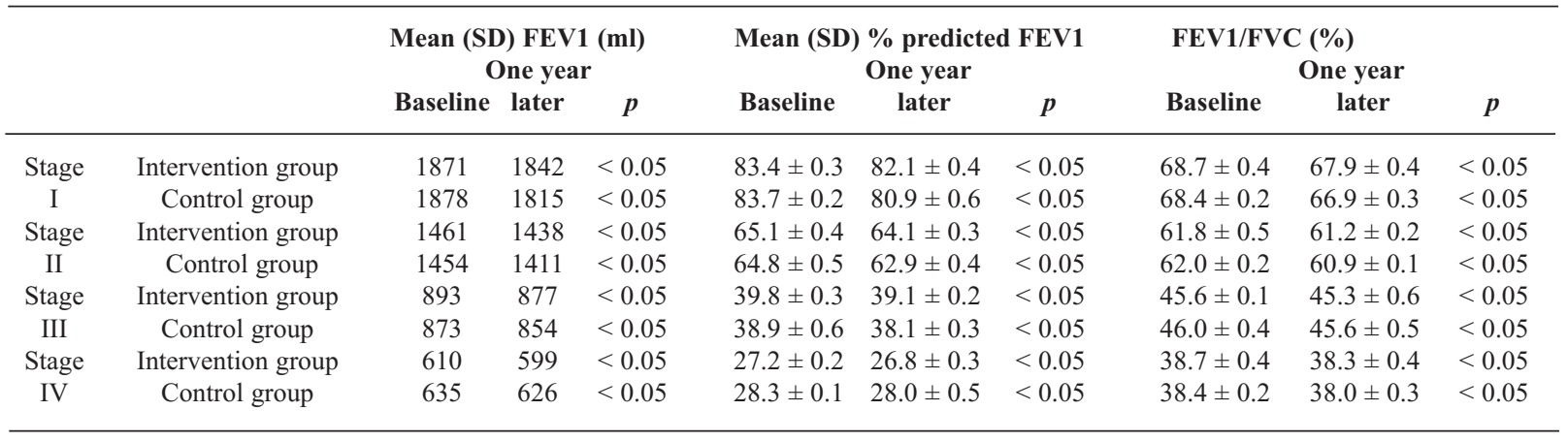

control groups, but the values of decline in FEV1 were not significantly lower in the intervention groups of stage III and IV than the control groups. Similarly, the values of decline in FEV1/FVC were significantly lower in the intervention groups of stage I and II than the control groups, but the values of decline were not significantly lower in the intervention groups of stage III and IV than the control groups (Table 3).

Table 3: Value of decline in FEV1 (ml, predicted \%/year) and FEV1/FVC ratio $(\%)$ between intervention and control group

\begin{tabular}{llccc}
\hline & & $\begin{array}{c}\text { Intervention } \\
\text { group (\%) }\end{array}$ & $\begin{array}{c}\text { Control } \\
\text { group (\%) }\end{array}$ & $\boldsymbol{p}$ \\
\hline Stage I & Mean (SD) FEV1 (ml) & $29 \pm 4.2$ & $63 \pm 5.6$ & $<0.05$ \\
& Mean (SD) \% predicted FEV1 & $1.3 \pm 0.3$ & $2.8 \pm 0.4$ & $<0.05$ \\
& FEV1/FVC ratio (\%) & $0.8 \pm 0.1$ & $1.5 \pm 0.2$ & $<0.05$ \\
Stage II & Mean (SD) FEV1 (1) & $23 \pm 3.5$ & $43 \pm 4.1$ & $<0.05$ \\
& Mean (SD) \% predicted FEV1 & $1.0 \pm 0.4$ & $1.9 \pm 0.2$ & $<0.05$ \\
& FEV1/FVC ratio (\%) & $0.6 \pm 0.1$ & $1.1 \pm 0.2$ & $<0.05$ \\
Stage III & Mean (SD) FEV1 (1) & $16 \pm 2.7$ & $19 \pm 2.3$ & $>0.05$ \\
& Mean (SD) \% predicted FEV1 & $0.7 \pm 0.5$ & $0.8 \pm 0.7$ & $>0.05$ \\
& FEV1/FVC ratio (\%) & $0.3 \pm 0.3$ & $0.4 \pm 0.6$ & $>0.05$ \\
Stage IV & Mean (SD) FEV1 (1) & $11 \pm 2.5$ & $9 \pm 2.1$ & $>0.05$ \\
& Mean (SD) \% predicted FEV1 & $0.4 \pm 0.1$ & $0.3 \pm 0.2$ & $>0.05$ \\
& FEV1/FVC ratio (\%) & $0.4 \pm 0.2$ & $0.4 \pm 0.3$ & $>0.05$ \\
\hline
\end{tabular}

FEV1 - forced expiratory volume in one second; FVC - forced vital capacity

The ratios of patients with acute exacerbation were lower in the intervention groups than the control groups (Table 4).

Table 4: Ratio of COPD patients with acute exacerbation in one year between intervention and control group at all stages

\begin{tabular}{llccc}
\hline & $\begin{array}{c}\text { Intervention } \\
\text { group (\%) }\end{array}$ & $\begin{array}{c}\text { Control } \\
\text { group (\%) }\end{array}$ & $\boldsymbol{p}$ \\
\hline Stage I & Ratio (SD) & $0 \pm 0$ & $7.0 \pm 3.38$ & $<0.05$ \\
Stage II & Ratio (SD) & $4.8 \pm 3.30$ & $11.9 \pm 4.50$ & $<0.05$ \\
Stage III & Ratio (SD) & $7.8 \pm 3.06$ & $15.6 \pm 4.14$ & $<0.05$ \\
Stage IV & Ratio (SD) & $16.7 \pm 5.76$ & $34.1 \pm 7.40$ & $<0.05$ \\
\hline
\end{tabular}

COPD - chronic obstructive pulmonary disease

\section{DISCUSSION}

The results showed that early intervention could slow the decline of FEV1 and FEV1/FVC in patients with COPD in stage I and II, and thus delay the progression of COPD. Furthermore, the effect of early intervention was better in patients with COPD in stage I than stage II. But early intervention was useless in slowing the decline of FEV1 and FEV1/FVC in patients with COPD in stage III and IV. The ratios of patients with acute exacerbation in one year were lower in the intervention groups than control groups $(p<$ 0.05 ), thus early intervention could reduce the ratio of patients with acute exacerbation and improve the quality of life of patients with COPD.

Early intervention of COPD was mainly performed in hospital and the targets were patients with moderate and severe COPD (10). This was because pulmonary function test had not been included in regular surveillance and it was difficult to diagnose patients with COPD before they had severe symptoms and signs. Previous studies reveal that the main aims of early intervention in patients with COPD were to prevent acute exacerbation and improve the quality of life in the patients. The results of the present study are in keeping with these aims.

Recent studies reveal that FEV1 decreases faster in patients with COPD at an earlier stage, so we should pay particular attention to the patients with COPD in the earlier stages, high-risk populations and the general population. Early intervention can significantly slow the decline of FEV1 and FEV1/FVC, enhance the rate of smoking cessation and reduce cumulative mortality in the general population (9). This present study was a useful addition to previous studies, and furthermore found that the effect of early intervention was better in the patients with COPD in the earlier stages but early intervention had little effect on slowing the decline of FEV1 and FEV1/FVC when patients became severe.

As for the limitations of this study, firstly, the patient sample was too small for generalization. Secondly, as the progression of COPD is affected by many factors, the study did not include all the confounding factors, for example, family income, occupational exposure, educational back- 
ground and others. Lastly, the follow-up period of the study was too short to analyse the progression of COPD.

\section{CONCLUSION}

Early intervention could slow the decline of FEV1 and FEV1/FVC in patients with COPD at stages I and II and thus delay the progression of COPD. However, early intervention could not slow the decline of FEV1 and FEV1/FVC in patients with COPD at stages III and IV. Early intervention could prevent patients with COPD from acute exacerbation and improve the quality of life of patients at all the stages.

\section{ACKNOWLEDGEMENTS}

This project is supported by the Science and Technological Programme for Dongguan's Higher Education, Science and Research, and Health Care Institutions, China (project no. 20101051502401). They played no role in study design, data collection and analysis, decision to publish, or preparation of the manuscript. All the authors declare that there is no conflict of interests.

\section{REFERENCES}

1. Sin DD, Stafinski T, Ng YC, Bell NR, Jacobs P. The impact of chronic obstructive pulmonary disease on work loss in the United States. Am J Respir Crit Care Med 2002; 165: 704-7.

2. Lopez AD, Murray CC. The global burden of disease, 1990-2020. Nat Med 1998; 4: 1241-3.

3. Zhong N, Wang C, Yao W, Chen P, Kang J, Huang S et al. Prevalence of chronic obstructive pulmonary disease in China - a large populationbased spirometry based cross-sectional survey. Am J Respir Crit Care Med 2007; 176: 753-60.

4. Buist AS, McBurnie MA, Vollmer WM, Gillespie S, Burney P, Mannino $\mathrm{DM}$ et al. International variation in the prevalence of COPD (the burden of obstructive lung disease study): a population-based prevalence study. Lancet 2007; 370: 741-50.
5. Scanlon PD, Connett JE, Waller LA, Altose MD, Bailey WC, Buist AS. Smoking cessation and lung function in mild-to-moderate chronic obstructive pulmonary disease. The Lung Health Study. Chin J Respir Crit Care Med 2000; 161: 381-90.

6. Tashkin DP, Celli B, Senn S, Burkhart D, Kesten S, Menjoge S et al. A 4-year trial of tiotropium in chronic obstructive pulmonary disease. $\mathrm{N}$ Engl J Med 2008; 359: 1543-54.

7. Troosters T, Casaburi R, Gosselink R, Decramer M. Pulmonary rehabilitation in chronic obstructive pulmonary disease. Am J Respir Crit Care Med 2005; 172: 19-38.

8. Browner WS, DuChene AG, Hulley SB. Effects of the multiple risk factor intervention trial smoking cessation program on pulmonary function - a randomized controlled trial. West J Med 1992; 157: 534-8.

9. Anthonisen NR, Connett JE, Kiley JP, Altose MD, Bailey WC, Buist AS et al. Effects of smoking intervention and the use of an inhaled anticholinergic bronchodilator on the rate of decline of FEV1. The Lung Health Study. JAMA 1994; 272: 1497-505.

10. Zhou YM, Wang DL, Wang SY, Wang YJ, Liu ZG, Hu JX et al. Community based integrated intervention for prevention and management of chronic obstructive pulmonary disease (COPD) in Guangdong, China: cluster randomized controlled trial. BMJ 2010; 341: c6387. DOI: 10.1136/bmj.c6387.

Submitted 11 Dec 2013
Revised 12 Mar 2014
Accepted 17 Mar 2014
Published 30 Apr 2014
Online: http://myspot.mona.uwi.edu/wimjopen/article/65
(C) Lei et al 2014
This is an open access article made freely available under Creative
Commons Attribution 4.0 International (CC BY 4.0). Users are free to
share, copy and adapt this work as long as the copyright holder (author)
is appropriately and correctly credited. See http://creativecommons.
org/licences/by/4.0/deed.en_us for more information.

